\title{
Use of dietary linoleic acid for secondary prevention of coronary heart disease and death: evaluation of recovered data from the Sydney Diet Heart Study and updated meta-analysis
}

The authors of this Research paper would like to correct the funding section in the footnotes, which should have included more information on the study's funding sources in the second and third sentences (BMJ 2013;346:e8707, doi:10.1136/bmj. e8707). In its entirety, the funding section should have read: "The Life Insurance Medical Research Fund of Australia and New Zealand provided a grant in support of the SDHS. The Intramural Program of the National Institute on Alcohol Abuse and Alcoholism, National Institutes of Health, and the University of North Carolina Program on Integrative Medicine (National
Institutes of Health grant T-32 AT003378), supported data recovery and evaluation. The content is solely the responsibility of the authors and does not necessarily represent the official views of the National Institutes of Health. The funding source had no role in study design, data collection, analysis, interpretation, or writing of the report."

Cite this as: BMJ 2013;346:f903

๑ BMJ Publishing Group Ltd 2013 